\title{
LAND USE OPTIMIZATION USING THE FUZZY MATHEMATICAL- SPATIAL APPROACH: A CASE STUDY OF CHELGERD WATERSHED, IRAN
}

\author{
Moslem HEYDARI ${ }^{1, *}$, Afshin HONARBAKHSH${ }^{2}$, Mahdi PAJOOHESH ${ }^{3}$, \\ Maryam ZANGIABADI ${ }^{4}$
${ }^{1,2,3}$ Department of Watershed Management, Shahrekord University, Shahrekord, the Islamic Republic of Iran
${ }^{4}$ Department of Applied Mathematics, Shahrekord University, Shahrekord, the Islamic Republic of Iran

Received 24 November 2016; accepted 30 June 2017

\begin{abstract}
In recent years, inappropriate land use, urban and industrial development along with different pollutions emanating from it gives rise to loss of natural resources and further leads to destructive floods, soil erosion, sedimentation and other various environmental, economic and social damages. Thus, management and planning are essential for the proper utilization, protection and revival of these resources. This study aimed to develop a mathematical-spatial optimum utilization model using FGP - MOLA in watershed including environmental and economic objectives while considering social issues. The results showed that the proposed model can lead to economic growth to $37 \%$ and decreasing the environmental damages to $2.4 \%$. Under optimized condition, the area allocated to dry farming lands will decrease about $12 \%$ and gardens will increase about $423 \%$ and the other land uses remain unchanged too. In addition to, the results demonstrated the usefulness and efficiency of the proposed fuzzy model due to its flexibility and capability to simultaneously provide both optimum values and location of production resources.
\end{abstract}

Keywords: water, land, environment, utilization, management, optimization model.

\section{Introduction}

Nowadays, due to the absence of integrated watershed management in most regions, natural resources have caused numerous damages with severe floods as one of its consequences which further leads to economic, social and environmental damages. Recently, there is no optimal utilization of land in most watersheds; hence there is no optimal model to account for the facilities and objectives used in the watersheds.

As a means of exploitation of natural resources, watersheds have always been considered by policy makers and planners of countries for sustainable development. Meanwhile, the logical and systematic use of upstream resources that eliminate dangers for downstream areas has been regarded as one of the most important policies of natural resources managers. Thus, the use of multi-objective decision making methods of planning such as goal programming (GP) will be useful for optimal land allocation.

Since Zayandehrood dam, located at the downstream of Chelgerd watershed (a part of Zayandehrood river basin), provides the drinking and agricultural water of both Chaharmahal and Bakhtiari Province and Esfahan Province, proper management of this watershed is critical. This procedure is based on the principles of economy and relies on the existing resources and their proper management and planning. Therefore, this method is not costly in practice.

According to Rockstrom and Karlberg (2010) natural resources management leads to numerous profits in the watershed including the increase of food products, improvement of livelihood, environmental protection, determining ownership type as well as current concerns about environmental diversity. Haregeweyn et al. (2012) used integrated watershed management as an effective approach to the problem of land destruction in Anaberd watershed in the north of Ethiopia. In this study, the effects of integrated watershed management including landuse change, reduction of water runoff and soil erosion, consequently sheet erosion, rill erosion and Gully erosion, have been investigated.

Using GP, Fooks and Messer (2012) maximized the protection of forests in the US. They concluded that GP is

${ }^{*}$ Corresponding author. E-mail: heydari_moslem@yahoo.com 
flexible enough for the manager to consider both ecological and political factors.

Fuzzy goal programming (FGP) method was employed by Pal et al. (2003) to resolve agricultural programming problems. In applied procedure, objectives and constraints were fuzzy and deterministic, respectively. Both concluded that this method allows the decision makers to determine the significance of individual objectives. They stated that proposed procedure is more compatible with the agricultural environment.

Asadpoor et al. (2005) attempted to optimize the agricultural land use model using the FGP approach and resulted that the FGP model allocates the resources in a better way by making the goals flexible. In a research, Han et al. (2011) reviewed the development of a multi objective procedure using interval parameters. The developed model was implemented for the allocation of water resources with different qualities to urban, agricultural and industrial consumers in Dalian City, China. This method maximizes the economic, social and environmental profits. The results showed that the ratio of the reused water to the entire water is on a gradual increase, hence, there was a decrease in the ratio of agricultural water consumption to the entire water consumption.

Amini (2013) implemented the FGP approach in the east of Isfahan. The quantitative analysis of the obtained findings suggested the superiority of the FGP approach over other models, in terms of simultaneous access to objectives. Alphan and Guvensoy (2016) applied a quantitative approach for evaluating spatiotemporal changes in land use and terrain cover in the eastern Mediterranean coast of Turkey. They concluded that the areas of urban, agricultural, and shrub lands were changing rapidly.

Some researchers applied other procedures in watershed management. For example, Graymore et al. (2009) used the decision support system (DSS) for the analysis and management of water projects in Glenelg Hopkins Catchment, in Australia. They stressed on the direct involvement of beneficiaries in the decision making process, as well as the significant role of DSS in effective project management. In a study for forest watershed management, Segura et al. (2014) applied the decision support system. Sahnoun et al. (2012) used techniques like ELECTRE to analyze the land use proportion. In a research, Lehmann et al. (2013) examined the effect of climate change, and the cost risks on crops management decisions, in the Switzerland usingan economic model based on the algorithm genetics. The results showed that the effects of costs change on the optimal management decisions are more than the effect of climate change. Porta et al. (2013) presented a performance genetic algorithm for programming land use through the use of constraints to be imposed and the variables to be optimized were selected on the basis of the current national, local laws and the criterions of experts. The results showed the efficiency of genetic algorithm in addressing the issues. Liu et al. (2013) introduced a fuzzy inference system for the evaluation of fuzzy algorithm based on a multi-criteria assessment to build a self-adapting system. The results indicated that the proposed model is very efficient. Haque and Asami (2014) carried out the optimal allocation of urban land uses through the use of an optimization generic algorithm model and applied a multi-objective function which simultaneously maximized the price of land and reduced the incompatibility between adjacent land uses. The results showed the simplification of the decision on land allocation. Shaygan et al. (2014) used the non-dominated sorting genetic algorithm (NSGA)-II for land use planning in Taleghan watershed. The results obtained from their research indicated that Economic return after optimization increased, while soil erosion decreased and the amount of runoff and soil erosion are important parameters in land use optimization. Stewart and Janssen (2014) used a special purpose genetic algorithm to produce an optimization model for land use planning in a region of the Netherland. The model produced showed consistent results in which the spatial distribution of activities are the same as with the more complex model of spatial goals, achievable. Xiaoya and Xiang (2015) surveyed the application of land use allocation model based on a multi-objective artificial clonal algorithm in China and it was found that the optimized model will offer improvements in viewpoint of the social and ecological objectives. In a study, Mohammadi et al. (2015) used NSGA-II to produce a plan with the purpose of sustainable development. They demonstrated the effectiveness of this algorithm through representation of optimal solutions with different priority and better application of non-linear objective functions in comparison to linear functions. Memmah et al. (2015) presented a review of 38 case studies about land use optimization using metaheuristics. Some of their conclusions are as follows: "the success of metaheuristics is problem-dependent and a future challenge is the use of parallelization techniques along with the hybridization of different metaheuristics or of metaheuristics with other optimization methods". Harshada et al. (2015) stated that "Optimization of land use can be attained functionally through Floor Space index (FSI)".

In fact, the conveyed classic optimization methods perform mathematical optimization but are unable to perform spatial optimization. Thus, the use of integrated methods can lead to results that are mathematically and spatially optimal. Eastman et al. (1995) developed a spatial procedure of multi-objective land allocation (MOIA) for multi-criteria analysis (MCA) and multi-objective analysis (MOA) decisions. Benjamin (2001) used a multicriteria evaluation in addition to a basic spatial DSS using MOLA in the area of Baringo in Kenya, for decision making about land use allocation. In a research conducted in Dongguan area of China, a combination of remote sensing and geographical information system (GIS)were used by $\mathrm{Li}$ in investigating land use and presenting a sustainable model for land allocation. Abubakar et al. (2012) conducted a research in the Eastern North of Nigeria aimed at determining areas in which there are possible terms of 
desertification up to 2030. In the research, the Markov chain was employed in anticipating optimization techniques of MOLA which had been used for mapping. Furthermore, Jereon et al. (2013) used regression logistic and MOLA in anticipating the spatial distribution of organic carbon of soil throughout France.

Also, some researchers studied other aspects of environmental protection. For example, Li and Zhao (2017) usedcellular automata model for "assessment of future urban growth impact on landscape pattern", Zhu et al. (2017) studied "effects of urban green belts on the air temperature, humidity and air quality", Liang et al. (2017) appliedlandscape metrics for "assessing urban green space distribution in a compact megacity", Shirazi et al. (2016) investigated "runoff trend and potentiality in Melaka Tengah catchment of Malaysia using SCS-CN and statistical technique", Maheshwari (2016) studied "the performance of irrigation systems around homes".

The aim of this study was to use the fuzzy mathematical-spatial optimization approach to develop an efficient utilization plan, so as to maximize profit and minimize sedimentation through optimal land allocation. Another purpose of this study was to determine both optimum values and locations of production resources.

\section{Materials and methods}

The study area is one of the mountainous watersheds located in the west of Iran and has a mean altitude of $2541.74 \mathrm{~m}$ from sea level, an area of about 13580 ha and average slope of $24.45 \%$. As regards climatic conditions, this watershed has an average annual rainfall of about $1350 \mathrm{~mm}$ and an average annual temperature of about $9{ }^{\circ} \mathrm{C}$. According to Pajoohesh et al. (2011) who used the
USLE model, the average amount of erosion in this watershed is about 15.02 tons/ha in a year; sediment delivery ratio using the calibrated Renfro (1975) model is about $24 \%$, and consequently, the amount of sediment yield is about 3.6 tons/ha in a year (Figure 1). Some other more influential factors of environmental sustenance are: soil texture, which is approximately silty clay loam, as it contains silt $43.8 \%$, clay $18.6 \%$, sand $16.9 \%, \mathrm{CaCo}_{3} 19 \%$, organic material $1.7 \%$, cation exchange capacity (CEC) equal to $40(\mathrm{cmol} / \mathrm{kg})$ and maximum infiltration rate of $1.33(\mathrm{in} / \mathrm{h})$. The water quality is good and located in class C1S1 in the Vilcox diagram because of the sodium adsorption ratio of about 2 and electrical conductivity of about 500 ( $\mu$ mohs/ $\mathrm{cm})$. Astragalus-Daphne is the dominant vegetation type in this region.

\subsection{Data collection}

To effectively conduct this research, the watershed boundary was first delineated by the ILWIS software using maps at a scale of 1:25000 and physical parameters of the watershed which includes perimeter and area etc. were extracted. Then, the land use map was prepared using 1:25000 scale topography maps and Google Earth satellite images. This map was controlled in the field work and adapted to

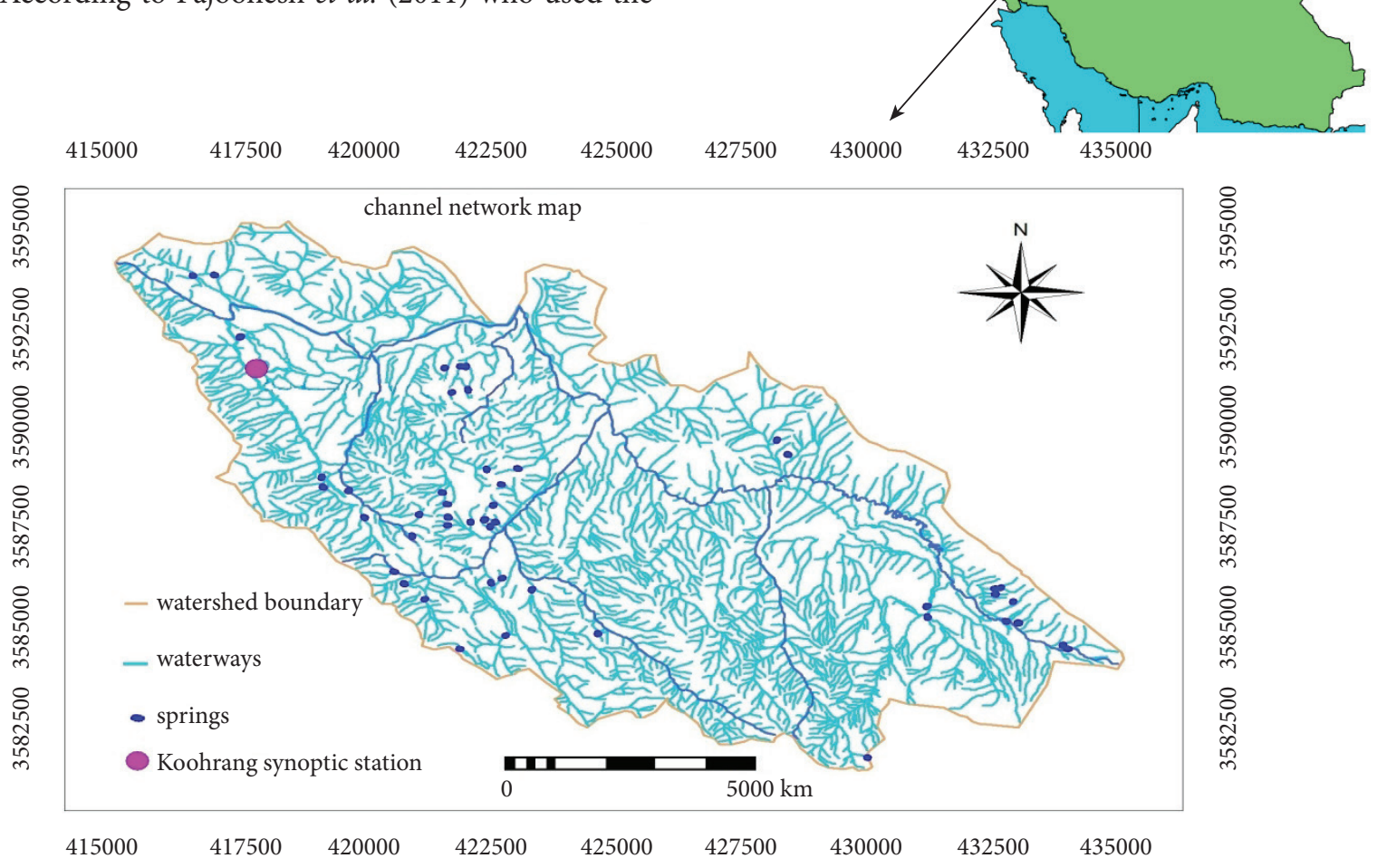

Figure 1. Position of the studied watershed 
real conditions. Investigation of the land use map reveals the development of residential areas, especially the city of Chelgerd, gardens and water installations. In preparing the exact average watershed slope map, the contour map was first made using a scale of 1:25000 with contour intervals of $20 \mathrm{~m}$. Thereafter, the map of summits was prepared. Next, to avoid creating flat areas on the site of summits, contour map and summits map were integrated and digital elevation model (DEM) was made on the basis of the integrated model (see Figure 1A in the Appendix) to create a precise average slope of the watershed (see Figure $2 \mathrm{~A}$ in the Appendix).

Other basis maps produced include: roads map, the channel network map and some long water ways of watershed, springs map, water installations map, the map of residential areas, the map of settlement regions for nomads, mines map, gardens map, the map of agricultural lands, the separated map of agricultural lands of dry farming as well as irrigated agriculture areas, rangelands map, the map of rock mass lands, and lastly the separable map of manageable and unmanageable areas were prepared (see Figure $3 \mathrm{~A}$ in the Appendix). In this case, after preparing the current land use map, areas with no possibility of land use change, such as residential areas, roads, rock mass lands, wetlands, and reservoirs of dams, were separated from the entire watershed area and the remaining areas with the possibility of land use change were considered as management areas.

Figure 3A shows the watershed areas in which there is the possibility of management and planning. The map also illustrates the current land use of these lands.
To investigate the criterion of accessibility to water in the study area, the available data of surface and ground water in the region were first obtained. To estimate the amount of available water in the area of interest, crop water requirement (CWR) for the dominant plant and tree species (fruit and fruit less trees) in the area should be calculated. Therefore, by interviewing the different beneficiaries of the watershed in the field work, water constraints experienced, and the forms of irrigation as well as the approximate amount of crop water requirement were investigated. Thereafter, using meteorological information and the FAO Penman-Montieth method, ETo and CWR were calculated more precisely (Tables 1 and 2). It should also be mentioned that the USDA Soil Conservation Service method was used for effective rain calculation (Allen et al. 1998). Finally, by comparing accessible water (the amount of water available in the watershed on the basis of harvesting licenses of the Water Resources Corporation Bureau) with the required amount of water calculated, no constraint about water was observed for developing gardens, irrigated agricultural lands and forest plantations.

For fruitless species depending on the experiences of beneficiaries, the CWR considered about $4000 \mathrm{~m}^{2} / \mathrm{ha}$. In calculating the utility coefficient of different land uses and cultivations as well as the dominant watershed trees, field visits along with general interview were first conducted with beneficiaries (ranchers, farmers and gardeners), and the initial information were collected. Thereafter, through the use of agricultural statistics and official information of the Natural Resources Department and agricultural organization in addition to subtracting the

Table 1. ETo (mm/day)

\begin{tabular}{|c|c|c|c|c|c|c|c|}
\hline \multirow{2}{*}{ Month } & Min Temp & Max Temp & Humidity & Wind & Sun & $\mathrm{Rad}$ & ETo \\
\hline & ${ }^{\circ} \mathrm{C}$ & ${ }^{\circ} \mathrm{C}$ & $\%$ & $\mathrm{~km} /$ day & hours & $\mathrm{MJ} / \mathrm{m}^{2} /$ day & $\mathrm{mm} /$ day \\
\hline January & -9.6 & 2.5 & 62 & 3 & 4.9 & 9.8 & 0.79 \\
\hline February & -9.5 & 2.5 & 63 & 5 & 5.2 & 12 & 0.99 \\
\hline March & -4.6 & 6.1 & 58 & 4 & 6.3 & 15.8 & 1.57 \\
\hline April & 0.6 & 11.1 & 51 & 4 & 7.3 & 19.5 & 2.36 \\
\hline May & 6.1 & 17.9 & 44 & 3 & 8.5 & 22.4 & 3.22 \\
\hline June & 9.6 & 24.9 & 31 & 2 & 11.4 & 27 & 4.16 \\
\hline July & 13.2 & 29.7 & 28 & 2 & 11.2 & 26.5 & 4.35 \\
\hline August & 14 & 30.2 & 28 & 2 & 10.3 & 24.1 & 4.01 \\
\hline September & 10.8 & 27.5 & 26 & 2 & 10.2 & 21.7 & 3.28 \\
\hline October & 6 & 21.5 & 34 & 2 & 8.9 & 17 & 2.23 \\
\hline November & 1.6 & 13.6 & 50 & 3 & 6.2 & 11.5 & 1.34 \\
\hline December & -4.6 & 6.8 & 57 & 3 & 5.1 & 9.3 & 0.89 \\
\hline
\end{tabular}

Table 2. Crop water requirement $\left(\mathrm{m}^{2} /\right.$ hectare $)$

\begin{tabular}{|c|c|c|c|c|c|c|}
\hline Crop name & Wheat & Barley & Alfalfa & Trifolium & Potato & Cucumber \\
\hline CWR & 3340 & 3230 & 390 & 390 & 3810 & 2760 \\
\hline Crop name & Bean & Chickpea & Almond & Walnut & Apple & Grape \\
\hline CWR & 2910 & 2630 & 3750 & 5630 & 3020 & 1590 \\
\hline
\end{tabular}


costs, the net profit obtained from any land use was calculated. It is one of the applied objective function coefficients $\left(C_{j}\right)$. Based on the importance of social issues in the management and planning of the watershed, field operations and interview with the various beneficiaries of the watershed were performed and the information obtained was used in the various stages of work implementation, such as discussion on land use comparisons, social problems like employment, constraints of water resources, etc. Also, another objective function coefficient considered in this study is the amount of sediment yield produced in each land use, and that was extracted from the study by Pajoohesh et al. (2011). Additionally, a two - factor cross map and the suitability land use map (measurement land use map) produced from it were made on the basis of slope, soil depth and accessibility of water resources criterion in the manageable areas using Guidelines and Bulletins of the FAO (1976, 1983, 1984, 1985, 1990 and 1992), (see Figures 4A and 5A in the Appendix). It is noteworthy that two factors, i.e. slope and soil depth criterion factors, are crossed when each level of one factor occurs in combination with a level of the other factor.

Information of this map together with ideas of the beneficiaries and managers of watershed are the core basis for determining the type of objectives and the values on the right-hand side (RHS) of constraints in the model.

\subsection{Model development and mathematical optimization}

In the case of fuzzy decision making, the intended goals of the decision makers comprising watershed managers, farmers, etc. are always fuzzy; even though constraints can be fuzzy or deterministic, depending on whether the available resources are fuzzy or not.

In the case of fuzzy decision making, the goals are determined by membership functions as well as the definitions of upper and lower tolerance limits. As regards the method used in this research, the goals are fuzzy and the fuzzy goal is one with a fuzzy aspiration level.

The general structure of the FGP model used in this research is based on Tiwari et al. (1986) as follows:

$$
\begin{gathered}
G_{1}: a_{11} x_{1}+a_{12} x_{2}+\ldots+a_{1 n} x_{n} \simeq B_{1}, \\
G_{2}: a_{21} x_{1}+a_{22} x_{2}+\ldots+a_{2 n} x_{n} \simeq B_{2}, \\
\cdot \\
\cdot \\
\cdot \\
G_{m}: a_{m 1} x_{1}+a_{m 2} x_{2}+\ldots+a_{m n} x_{n} \simeq B_{m}, \\
x_{i} \geq 0, i=1,2, \ldots, m, j=1,2, \ldots, n,
\end{gathered}
$$

The sign $\simeq$ in the mentioned goals indicate the fuzziness of the aspiration level, $\mathrm{m}$ is the number of goals, $\mathrm{n}$ is the number of decision variables and $B$ is the aspiration level or target value of goals. In this method, the membership functions $\mu_{\mathrm{i}}(G)$ should be defined for all fuzzy goals with fuzziness value of $\left(\Delta_{\mathrm{i}}\right)$ and then $2^{\mathrm{m}}$ subproblems using the minimum operator as bellow:

$$
\begin{aligned}
& \quad \text { Maximize }\left[\min \left\{\frac{\left(G_{i}\right)-B_{i L}}{\Delta_{i}}\right\}=\lambda\right], \\
& \text { s.t. } \mathrm{B}_{\mathrm{iL}} \leq \mathrm{G}_{\mathrm{i}} \leq \mathrm{B}_{\mathrm{i}}, \mathrm{i}=1,2, \ldots, \mathrm{m}, \\
& \text { i.e., } \operatorname{Max} \lambda \text {, } \\
& \text { s.t. } \lambda \leq \frac{\left(G_{i}\right)-B_{i L}}{\Delta_{i}}, \\
& \mathrm{~B}_{\mathrm{iL}} \leq \mathrm{G}_{\mathrm{i}} \leq \mathrm{B}_{\mathrm{i}}, \mathrm{i}=1,2, \ldots, \mathrm{m}, \\
& \lambda, \mathrm{x} \geq 0,
\end{aligned}
$$

and

$$
\operatorname{Maximize}\left[\min \left\{\frac{B_{i U}-\left(G_{i}\right)}{\Delta_{i}}\right\}=\lambda\right],
$$

s.t. $B_{i} \leq G_{i} \leq B_{i U}, i=1,2, \ldots, m$,

i.e., $\operatorname{Max} \lambda$,

s.t. $\lambda \leq \frac{B_{i U}-\left(G_{i}\right)}{\Delta_{i}}$,

$\mathrm{B}_{\mathrm{i}} \leq \mathrm{G}_{\mathrm{i}} \leq \mathrm{B}_{\mathrm{iU}}, \mathrm{i}=1,2, \ldots, \mathrm{m}$,

$\lambda, x \geq 0$,

In FGP modeling, most past researchers like Tiwari et al. (1986), first used the min operator to find fuzzy decisions that simultaneously satisfy the goals and constraints. Thereafter, the membership function of fuzzy decision making was used for maximization. The above method considers fuzzy decisions in relation to fuzzy goals and constraints, therefore there is no basic conflict between them. According to Tiwari et al. (1986) thus, "there will be the $2^{\mathrm{m}}$ problems taking into account the different combinations of membership functions of fuzzy goals. The subproblems are linear with single objective function which can be solved by linear programming techniques. The solution of that subproblem which has the highest membership value $(\lambda)$, yields the solution of the original FGP problem". In this study, two conflicting fuzzy goals corresponding to profit and sediment yield were considered while conducting the optimization in the watershed. The first goal was to correspond the total sediment yield in ton per year, while the second goal was to correspond the total profit in dollar (\$) such that, if possible, it should be obtained in terms of the aspiration levels of decision makers.

\subsection{Constraints}

The constraints emphasized in this study include limitations related to production resources and restrictions related to water resources, which in both cases, also involve social issues. In the case of production resources including land uses, the values on the right-hand side of constraints and the aspiration levels of fuzzy goals are specified in terms of watershed condition and the beneficiaries' viewpoints, which are correspondingly equal to the maximum or minimum surface area allocated to each land use. Given that the garden lands and irrigated cultivation needed to be watered, it was checked whether or not there is a constraint in terms of water resources in the 
basin. Furthermore, the measurement condition was considered in determining these values. Thus, for formulation and solving, the model conventional prioritization structure in GP will be used and in this step, the membership functions will be constructed linearly for the fuzzy goals according to the obtained information.

\subsection{Spatial optimization using multi-objective land allocation}

It is also necessary that in addition to the extraction of optimal area of land uses by the mentioned method, the optimal spatial situation of different land uses be determined, ensuring that it be performed using MOIA. To achieve this, the following steps were made:

First, the 12 fuzzy factor maps for slope and soil depth factors with equal importance were produced as criterion maps. These factors have monotonically decreasing and increasing linear membership functions for slope and soil depth, respectively. Also, these factors act as Boolean map that helps in determining suitable and unsuitable areas for each objective. Thereafter, using weighted linear combination (WLC) method, multicriteria evaluation (MCE) was done to produce six (6) suitability maps. MCE is a decision support tool for multi-criteria evaluation. It attempts to combine a set of criteria to achieve a single composite basis for a decision according to a specific objective. For instance, in order to make a decision about what areas are the most suitable for each land use development, the criteria are slope gradient and soil depth. An MCE combines criteria images representing suitability to form a single suitability map from which the final decision will be made. In this study, the WLC procedure is used as the combination method for the MCE. In this method, the criteria may include both weighted factors and constraints (Boolean maps). WLC starts by multiplying each factor by its factor weight and then adding the results. Constraints are then applied by successive multiplication to zero out excluded areas. In this research, factors had equal weights.

Next, the cell rank transformation of these maps was done by employing descending and ascending sorting process and 6 ranked suitability maps were produced. In this step, the optimal area of objectives were received with equal weights, MOLA was used in conducting the initial allocation and conflict resolution processes and finally the optimized spatial land use map was prepared (Figure 3). This method was performed using the IDRISI software.

\subsection{Performing sensitivity analysis on the objective functions}

In LP problems, the possible impacts of coefficients and variables on the value of objective functions and optimal solutions can be examined, after obtaining an optimal solution. Sensitivity analysis is a technique used to evaluate the degree of sensitivity of the optimal solution and objective function toward certain changes in the problems.

Figure 2 shows the flow chart of work process steps of the combined mathematical-spatial optimization model:

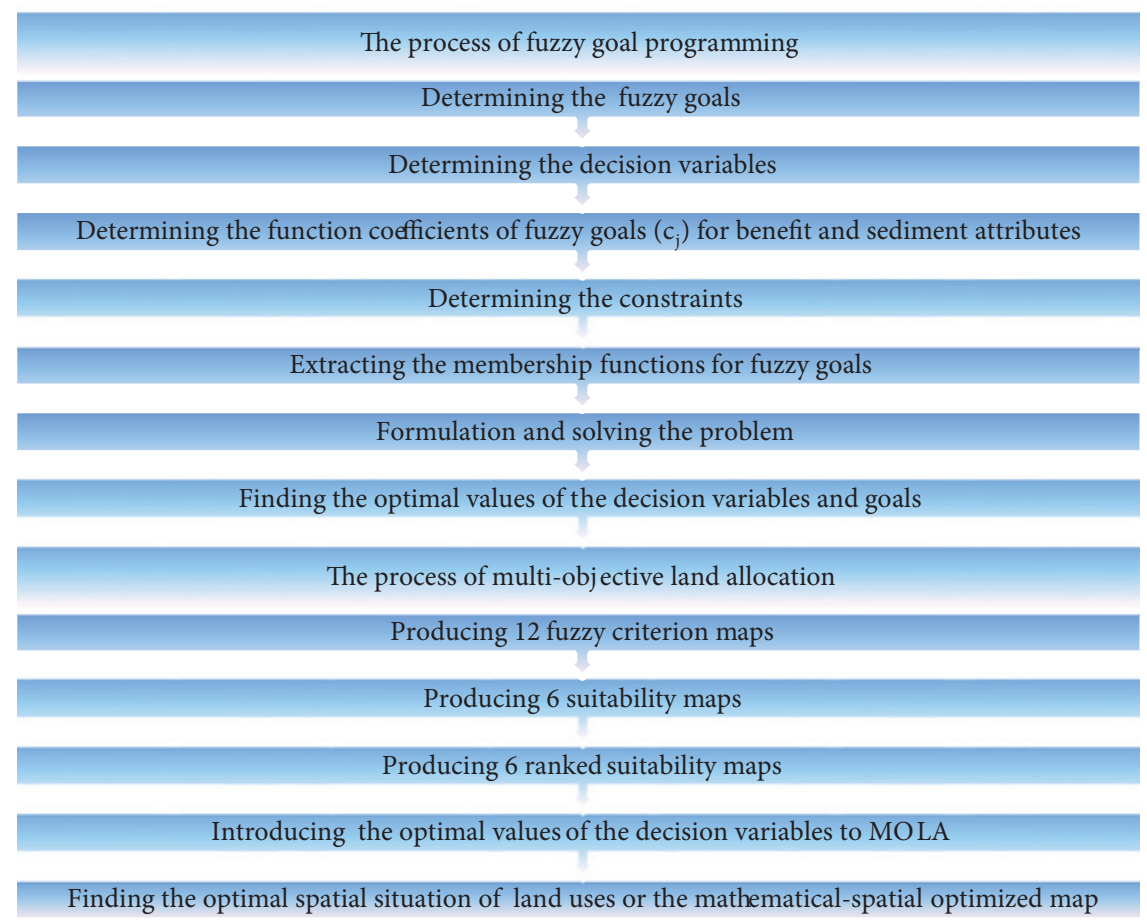

Figure 2. The flow chart of work process steps 


\section{Results and discussion}

In this study, the subproblem which had a global optimal solution was formulated to the priority structure using LINGO software as follows:

Maximize $=\lambda$,

s.t. $\lambda<=\left(\left(29.39 \mathrm{x}_{1}+1008.75 \mathrm{x}_{2}+123.37 \mathrm{x}_{3}+2586.11 \mathrm{x}_{4}+\right.\right.$ $\left.\left.1782.25 \mathrm{x}_{5}+29.49 \mathrm{x}_{6}\right)-(2155339.63)\right) /(2258087.87)$

$\lambda<=\left(\left(3.39 \mathrm{x}_{1}+3.06 \mathrm{x}_{2}+3.61 \mathrm{x}_{3}+3.15 \mathrm{x}_{4}+1.22 \mathrm{x}_{5}+\right.\right.$ $\left.\left.3.36 \mathrm{x}_{6}\right)-(42837)\right) /(3059.44)$,

$3.39 \mathrm{x}_{1}+3.06 \mathrm{x}_{2}+3.61 \mathrm{x}_{3}+3.15 \mathrm{x}_{4}+1.22 \mathrm{x}_{5}+3.36 \mathrm{x}_{6}<=$ 45896.44

$3.39 \mathrm{x}_{1}+3.06 \mathrm{x}_{2}+3.61 \mathrm{x}_{3}+3.15 \mathrm{x}_{4}+1.22 \mathrm{x}_{5}+3.36 \mathrm{x}_{6}>=$ 42837 ,

$29.39 \mathrm{x}_{1}+1008.75 \mathrm{x}_{2}+123.37 \mathrm{x}_{3}+2586.11 \mathrm{x}_{4}+$ $1782.25 \mathrm{x}_{5}+29.49 \mathrm{x}_{6}<=4413427.5$,

$29.39 \mathrm{x}_{1}+1008.75 \mathrm{x}_{2}+123.37 \mathrm{x}_{3}+2586.11 \mathrm{x}_{4}+$ $1782.25 \mathrm{x}_{5}+29.49 \mathrm{x}_{6}>=2155339.63$,

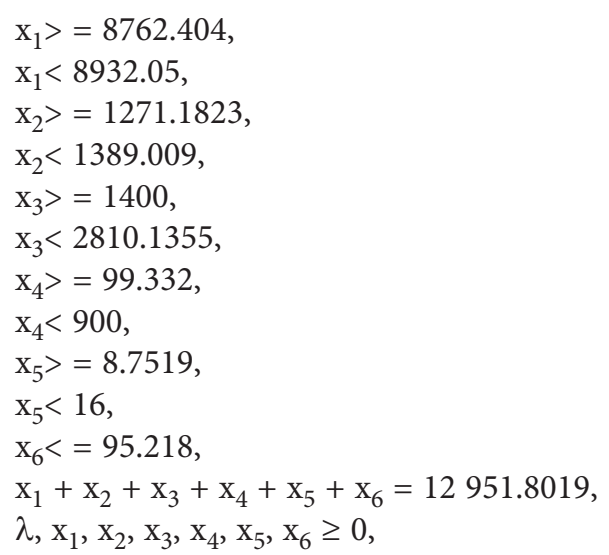

where, $\mathrm{x}_{1}, \mathrm{x}_{2}, \mathrm{x}_{3}, \mathrm{x}_{4}, \mathrm{x}_{5}$, and $\mathrm{x}_{6}$ are the decision variables of the model showing the amount of land that must be allocated to the rangeland, irrigated agriculture, dry farming, garden, forest plantation and forest land uses, respectively. This study is aimed at determining a feasible solution to this problem. A solution which presents the nearest value to the desirable aspiration levels in terms of profit and sediment yield while considering the constraints of the problem is the optimal solution to this problem. The linear membership functions for fuzzy goals with fuzziness values $\Delta_{1}=3059.44$ and $\Delta_{2}=2258087.87$ chosen by the DMs are as follows:

$\mu_{1}\left(G_{1}\right)=\left\{\begin{array}{cl}1 & \text { if } G_{1}=45896.43, \\ 0 & \text { if } G_{1} \leq 42836.99, \\ \frac{\left(G_{1}\right)-42836.99}{3059.44} & \text { if } 42836.99 \leq G_{1} \leq 45896.43, \\ \frac{48955.88-\left(G_{1}\right)}{3059.44} & \text { if } 45896.43 \leq G_{1} \leq 48955.88, \\ 0 & \text { if } G_{1} \geq 48955.88,\end{array}\right.$

and

$$
\mu_{2}\left(G_{2}\right)= \begin{cases}1 & \text { if } G_{2}=4413427.50 \\ 0 & \text { if } G_{2} \leq 2155339.63 \\ \frac{\left(G_{2}\right)-2155339.63}{2258087.87} & \text { if } 2155339.63 \leq G_{2} \leq 4413427.50 \\ \frac{6671515.37-\left(G_{2}\right)}{2258087.87} & \text { if } 4413427.50 \leq G_{2} \leq 6671515.37 \\ 0 & \text { if } G_{2} \geq 6671515.37\end{cases}
$$

The membership function values $(\lambda)$ for the optimal solution is 0.35 . In the fuzzy model in this study, the goals are just fuzzy and the other items are crisp. For future research, other parts, such as objective function coefficients, the RHSs, and constraints, can also be fuzzy. The FGP method was employed by Biswas and Pal (2003) to resolve agricultural programming problems on the condition that both constraints and objectives were fuzzy. Table 3 shows the solution values for decision variables of the model. The solution for the problem is lexicographically optimal because there is no other solution lexicographically better than it in the ordered goals.

Table 3. The solution values for the model

\begin{tabular}{|c|l|c|}
\hline $\begin{array}{c}\text { Decision } \\
\text { Variable }\end{array}$ & \multicolumn{1}{|c|}{ Land Use } & $\begin{array}{c}\text { Solution Value } \\
\text { (hectare) }\end{array}$ \\
\hline $\mathrm{x}_{1}$ & rangeland & 8762.40 \\
\hline $\mathrm{x}_{2}$ & irrigated agriculture & 1271.18 \\
\hline $\mathrm{x}_{3}$ & dry farming & 2497.37 \\
\hline $\mathrm{x}_{4}$ & garden & 412.09 \\
\hline $\mathrm{x}_{5}$ & forest plantation & 8.75 \\
\hline $\mathrm{x}_{6}$ & forest & 0 \\
\hline
\end{tabular}

The optimal solution for the model under consideration had a goal value of $G_{1}$ equal to 2950708.96 million $\$$ annually and $G_{2}$ equal to 43881.49 tons per year with both demonstrating under achievement of about 33 and $4 \%$, respectively. Table 4 reveals the total contribution of decision variables to the objective functions, the reduced cost values and the optimality range. The total contribution of a decision variable to the objective function is obtained by multiplying its final solution by the objective function coefficient. As can be observed in Table $4, \mathrm{x}_{2}$ or irrigated agricultures in $G_{1}$ and $x_{1}$ or rangelands in $\mathrm{G}_{2}$ contributed more to the objective functions. Also, Table 4 shows that in the model, all decision variables except $\mathrm{x}_{6}$ which is non-basic due to having non-zero reduced cost, had a reduced cost of 0 and are basic variables that exist in the optimal solution. The reduced cost of a variable indicates the amount of penalty one would have to pay to introduce one unit of that variable into the solution. Furthermore, allowable minimum and maximum values of objective function coefficients are shown in this table. Range of optimality or sensitivity analysis for goal (objective function) shows the ranges of the goal or 
objective function coefficients such that the current basis holds. For each decision variable, this includes the lower limit and upper limit allowed for its objective function coefficient so that the variable stays in basis, that is a basic variable.

From Table 5, in the model, there was an equal corresponding maximum decrease for $\lambda$ in $\mathrm{C} 2, \mathrm{C} 4, \mathrm{C} 5, \mathrm{C} 6$, C7, C8, C10 and C11. The overall land uses had a shadow price of 0 . Furthermore, according to Table 5, in the model, a corresponding maximum decrease was noticed in C9, C3 and C1 due to greater value of shadow price. The slack and surplus variables are the variables added to the constraints to convert them into equalities necessary for solving the problem. The slack variable is the starting basic variable for the constraint. In addition, it can be interpreted as the unused resource or RHS. Moreover, the surplus variable can be interpreted as the amount over the requirement or right-hand side. Sensitivity analysis for RHS (range of feasibility) shows the ranges of the right-hand sides such that current basis holds. For each constraint, this includes the lower limit and upper limit allowed for its right-hand side so that the current basic variable is still feasible.
The results indicated that people are still making use of land that does not follow the optimized procedure in the current condition. On the other hand, in the current conditions, land use is experimental and somewhat random and unscientific. Under optimized conditions, the area allocated to dry farming lands will decrease by about $12 \%$ and gardens will increase by about $423 \%$ while other land uses remain unchanged.

The sensitivity analysis of the objective function coefficient $\left(c_{j}\right)$ revealed that $c_{1}$ and $c_{2}$ are the most important coefficients and their changes gave rise to further changes in the objective function solution. As $\mathrm{c}_{1}$ decreased by $5 \%$, the amount of sediment yield decreased by about $3 \%$, and as $c_{2}$ increased by $5 \%$, the profit increased by about $2 \%$, respectively. In this case, one of the objective function coefficients increases by $5 \%$ while other factors were kept constant. This was repeated for other coefficients and the effects of changes in each coefficient on the objective function value were determined. Each coefficient that caused the greatest changes in the value of the objective function was selected as the most sensitive.

Figure 3 shows the result of performing spatial optimization. In fact, it is the optimized land use map of the

Table 4 . The total contribution and reduced cost values of decision variables for the model

\begin{tabular}{|c|c|c|c|c|c|}
\hline \multirow{2}{*}{$\begin{array}{l}\text { Decision } \\
\text { Variable }\end{array}$} & \multicolumn{2}{|c|}{$\begin{array}{c}\text { Total } \\
\text { Contribution }\end{array}$} & \multirow{2}{*}{$\begin{array}{l}\text { Reduced } \\
\text { Cost }\end{array}$} & \multicolumn{2}{|c|}{ Range of Optimality } \\
\hline & $\begin{array}{c}\mathrm{G}_{1} \text { (Attribute: } \\
\text { Benefit) }\end{array}$ & $\begin{array}{l}\mathrm{G}_{2} \text { (Attribute: } \\
\text { Sediment) }\end{array}$ & & $\begin{array}{c}\text { Allowable Decrease } \\
C_{\mathrm{j}}\end{array}$ & $\begin{array}{l}\text { Allowable Increase } \\
\mathrm{C}_{\mathrm{j}}\end{array}$ \\
\hline $\mathrm{x}_{1}$ & 257533.56 & 29673 & 0 & 0.00006 & $+\infty$ \\
\hline $\mathrm{x}_{2}$ & 1282306.84 & 3883.71 & 0 & 0.0001 & $+\infty$ \\
\hline $\mathrm{x}_{3}$ & 307013.56 & 8989.02 & 0 & 0.002 & 0.00006 \\
\hline $\mathrm{x}_{4}$ & 1088256.92 & 1325.04 & 0 & 0.0001 & 0.0002 \\
\hline $\mathrm{x}_{5}$ & 15598.06 & 10.71 & 0 & 0.0005 & $+\infty$ \\
\hline $\mathrm{x}_{6}$ & 0 & 0 & 0.00007 & 0.00007 & $+\infty$ \\
\hline
\end{tabular}

Table 5. The Constraint Summary for the model

\begin{tabular}{|c|c|c|c|c|}
\hline \multirow[b]{2}{*}{ Constraint } & \multirow[b]{2}{*}{$\begin{array}{c}\text { Slack } \\
\text { or Surplus }\end{array}$} & \multicolumn{2}{|c|}{ Range of Feasibility } & \multirow[b]{2}{*}{$\begin{array}{c}\text { Shadow } \\
\text { Price }\end{array}$} \\
\hline & & Allowable Decrease RHS & $\begin{array}{c}\text { Allowable } \\
\text { Increase } \\
\text { RHS }\end{array}$ & \\
\hline $\mathrm{C} 1$ & 0 & 329.52 & 169.64 & -0.00006 \\
\hline $\mathrm{C} 2$ & 169.64 & 169.64 & $+\infty$ & 0 \\
\hline C3 & 0 & 596.23 & 117.82 & -0.0001 \\
\hline $\mathrm{C} 4$ & 117.82 & 117.82 & $+\infty$ & 0 \\
\hline C5 & 1088.65 & $+\infty$ & 1088.65 & 0 \\
\hline C6 & 321.48 & 321.48 & $+\infty$ & 0 \\
\hline C7 & 321.47 & $+\infty$ & 321.47 & 0 \\
\hline $\mathrm{C} 8$ & 479.19 & 479.19 & $+\infty$ & 0 \\
\hline C9 & 0 & 8.75 & 7.24 & -0.0005 \\
\hline $\mathrm{C} 10$ & 7.24 & 7.24 & $+\infty$ & 0 \\
\hline $\mathrm{C} 11$ & 95.21 & 95.21 & $+\infty$ & 0 \\
\hline
\end{tabular}




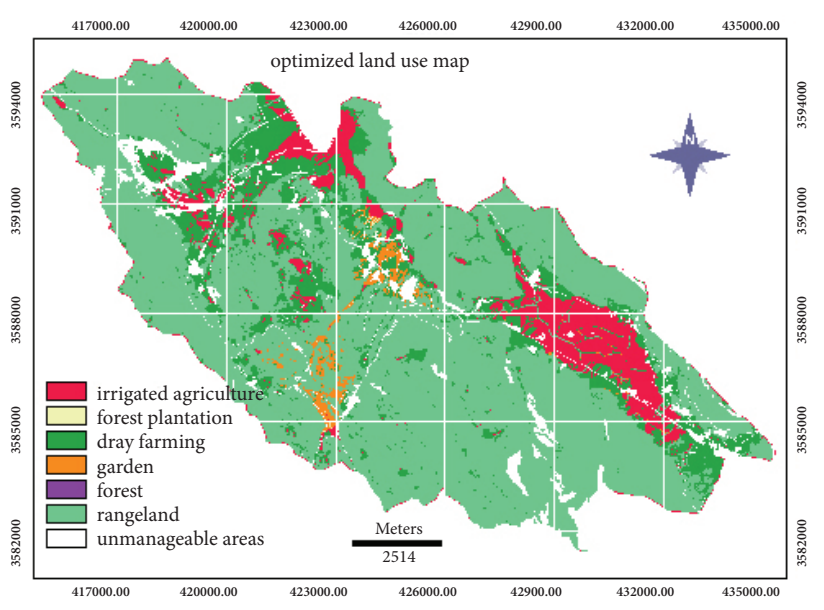

Figure 3. Optimized land use map of the studied watershed

watershed for the future. As its obvious land use structure indicates some displacement of land uses as a result of their optimal spatial allocation on the basis of the FAO land use measurements and also, some area development of garden and decrease of dry farming lands. As shown in Figure 3 and Table 3 , in the optimal conditions, the rangelands have the most value of area and the dry farming lands located at the margins of irrigated agricultures. In addition, among the useful results of the implementation of this plan that will lead to considerable development in the watershed includes: the results reveal the possibility of increasing the amount of annual profit obtained in this region from various land uses by about $37 \%$. The integrated land use management gives rise to sustainable development of natural resources, as well as their conservation and rehabilitation. Water resources management aims to solve the menace of water deficiency in the rural areas located in DashteZarin region with the use of pressurized irrigation instead of traditional irrigation methods with the least possible cost.

An estimation of CWR reveals that in pressurized irrigation condition, about 3.5 million cubic meters of water is needed while in the current condition about 20 million cubic meters were spent on traditional irrigation. In this case, transferring the water with the lowest possible cost for developing the pressure drip and rain irrigations will solve all the problems of water shortage of Dashte-Zarin and its rural environment and consequently, the employment and migration problem of young people in this region will be brought to an end.

The results from this study can be beneficial for environmental protection as follow:

The reduction of soil sedimentation through land use optimization will occur. The results reveal that optimal plan implementation will lead to a reduction of about 5074.38 tons per year in soil loss and damages caused by it. There will be an occurrence of development of gardens regarding water and soil resources potential as well as the suitable topography and consequently, the creation of an economic change due to very high income of this type of land use. It should be noted that some profitable recreational projects will give rise to a considerable increase in profit.

The development of gardens and consequently, further growth of the tourism industry in the region is another advantage. In this case, applications of agro-forestry designs which are a combination of forage cultivation and gardens, will not only boost the profit, but will also reduce pressure on rangelands.

The results show the presence of areas prone to forest with an area of about 95 ha in the watershed, such that, while maintaining pastoral values, due to more infiltration of rain in the forest ecosystems, forest in these areas makes feeding the underground water tables to be better, cause the springs in the region to be filled, with all environmental and recreational values of forest added to the region. In general, decreasing the amount of land allocated to dry farming and increasing the area allocated to gardens, forest and forest plantation increases the infiltration of rainwater into the ground and decreases runoff, flood, soil erosion and sedimentation. Thus correct allocation of land will be influenced on reducing environmental damages and therefore causes management and protection of environment. This plan is based on the principles of economy and is dependent on the existing resources using proper management and planning. We employed FGP like Pal et al. (2003) to resolve problems present in deterministic constraints condition and fuzzy objectives, and concluded that this model allows decision makers (DMs) to determine the significance of individual objectives, and is more compatible with the agricultural environment. Like Asadpoor et al. (2005), we arrived at the conclusion that the FGP model allocates the resources in a better way by creating flexibility in the goals. Like Han et al. (2011), Fooks and Messer (2012) and Amini (2013), concluded that GP or FGP is flexible enough for the DMs to consider ecological, political, socio-economic and environmental factors. Like Shaygan et al. (2014), the results obtained from our research indicated that economic return after optimization increased, while soil erosion and sedimentation decreased. Some researchers have combined the LP model with other methods. For instance, after considering the comments and experiences of farmers Akbari and $\mathrm{Za}$ hedi Keyvan (2007) revealed that a combination of fuzzy hierarchical analytical method and the common linear programming (LP) model, produced more precise and compatible results with the real world condition.

\section{Conclusions}

A comparison of the area of lands allocated to various land uses in the current condition with the measurement condition and optimal condition as well as a consideration of the profit and sedimentation values changes, confirms the usefulness of this research. It should be noted that it is impossible to achieve the measurement map due to various constraints associated with available resources and socio-economic limitations in the basin. However, 
an optimization of the best scenario, that is, the closest case to this map will be introduced to the beneficiaries and managers, until the decision makers come up with policies in accordance with it and manage the watershed. Even though the advantages of some land uses with high income such as growing medicinal plants have not been incorporated into the above calculations, the results obtained from the optimal model show that the proper use can increase the profit up to $37 \%$ and decrease sediment yield to about $1 \%$. Furthermore, proper management of water resources can help address the problem related to water deficiency and drought as well as employment infrastructure, resulting in provision of socio-economic, cultural and tourism development in the region. The novelty of this study is as follows:

1 - So far, FGP is not used for optimization and land use planning in watershed and is only used in small farms for the planning their cultivation. 2 - FGP and MOLA have not been combined, in this study and for the first time, the two approaches were combined. 3 - Some studies conducted only the mathematical optimization of land uses without determining their optimal location, consequently, their results are incomplete for implementation in the real world. In other words, mathematically and spatially optimal results are more practicable and 4 - The combination of FGP - MOLA in terms of time has high performance and does not require much time while some approaches, such as genetic algorithms are very time-consuming.

\section{References}

Abubakar, A. M.; Efron, N. G.; Joseph, O. A. 2012. Remote sensing and GIS based predictive model for desertification early warning in north eastern Nigeria, Journal of Research 4(1): $1-14$.

Akbari, N.; Zahedi Keyvan, M. 2007. Application of fuzzy logic in determination of suitable crop cultivation pattern in a farm (Approach: fuzzy goal programming), Journal of Agricultural Economics 1(2): 13-35 (in Persian).

Allen, R. G.; Pereira, L. S.; Raes, D.; Smith, M. 1998. Crop evapotranspiration: guide-lines for computing crop water requirements, in FAO Irrigation and Drainage Paper No. 56. FAO, Rome, Italy.

Alphan, H.; Guvensoy, L. 2016. Detecting coastal urbanization and land use change in southern Turkey, Journal of Environmental Engineering and Landscape Management 24: 97-107. https://doi.org/10.3846/16486897.2015.1113976

Amini, A. 2013. Planning and optimal allocation of agricultural production resources under uncertainty; application of multiobjective fuzzy goal programming approach, Geography and Environmental Planning Journal 51(3): 107-128 (in Persian).

Asadpoor, H.; Khalilian, S.; Peykani, Gh. 2005. Theory and application of linear fuzzy goal programming model in crop cultivation pattern optimization, Journal of Agricultural Economics and Development 309: 307-338 (in Persian).

Benjamin, M. 2001. Land use conflicts resolution in a fragile ecosystem using Multi-Criteria Evaluation (MCE) and a GISBased Decision Support System (DSS), in International Conference on Spatial Information for Sustainable Development, 2-5 October 2001, Nairobi, Kenya. 11 p.
Biswas, A.; Pal, B. B. 2005. Application of fuzzy goal programming technique to land use planning in agricultural system, Omega Journal 33: 391-398. https://doi.org/10.1016/j.omega.2004.07.003

Eastman, J. R.; James, T.; Weigen, A.; Peter, A.; Kyem, K. 1995. Raster procedures for multi-criteria/multi-objective decisions, Photogrammetric Engineering \& Remote Sensing 61(5): 539-547.

FAO. 1976. A Framework for Land Evaluation. Soils Bulletin 32, Rome.

FAO. 1983. Guidelines: Land Evaluation for Rainfed Agriculture. Soils Bulletin 52, Rome.

FAO. 1984. Land Evaluation for Forestry. Forestry Paper 48, Rome.

FAO. 1985. Guidelines: Land Evaluation for Irrigated Agriculture. Soils Bulletin 55, Rome.

FAO. 1990. Guidelines: Land Evaluation for Extensive Grazing. Soils Bulletin 58, Rome.

FAO. 1992. Guidelines for land use planning. Prepared by the Interdepartmental Working Group on Land Use Planning. Soils Bulletin 66, Rome.

Fooks, J. R.; Messer, K.D. 2012. Maximizing conservation and in-kind cost share: Applying Goal Programming to forest protection, Journal of Forest Economics 18: 207-217. https://doi.org/10.1016/j.jfe.2012.04.001

Graymore, M. L. M.; Wallis, A. M.; Richards, A. J. 2009. An index of regional sustainability: a GIS-Based multiple criteria analysis decision support system for progressing sustainability, Ecological Complexity Journal 6: 453-462. https://doi.org/10.1016/j.ecocom.2009.08.006

Han, Y.; Huang, Y. F.; Wang, G. Q.; Maqsood, I. 2011. A multiobjective linear programming model with interval parameters for water resources allocation in Dalian city, Water Resource Management 25: 449-463. https://doi.org/10.1007/s11269-010-9708-7

Haque, A.; Asami, Y. 2014. Optimizing urban land use allocation for planners and real estate Developers, Computers, Environment and Urban Systems 46: 57-69. https://doi.org/10.1016/j.compenvurbsys.2014.04.004

Haregeweyn, N.; Berhe, A.; Tsunekawa, A.; Tsubo, M.; Tsegaye Meshesha, D. 2012. Integrated watershed management as an effective approach to curb land degradation: a case study of the enabered watershed in Northern Ethiopia, Environmental Management 50: 1219-1233.

https://doi.org/10.1007/s00267-012-9952-0

Harshada, R.; Bhede, M.; Arati, S. P. 2015. A study of land use planning and optimization, International Journal of Modern Trends in Engineering and Research 2(7): 956-964.

Jereon, M.; Anton, V. R.; Tim, Q.; Manuel, M.; Christian, P.; Dominique, A. 2013. Predicting future spatial distribution of SOC across entire France, Geophysical Research Abstracts, 15, $1 \mathrm{P}$.

Lehmann, N.; Briner, S.; Finger, R. 2013. The impact of climate and price risks on agricultural land use and cropmanagement decisions, Land Use Policy 35: 119-130.

https://doi.org/10.1016/j.landusepol.2013.05.008

Li, C.; Zhao, J. 2017. Assessment of future urban growth impact on landscape pattern using cellular automata model: a case study of Xuzhou city, China, Journal of Environmental Engineering and Landscape Management 25: 23-38. https://doi.org/10.3846/16486897.2016.1187620

Liang, H.; Chen, D.;Zhang, Q. 2017. Assessing Urban Green Space distribution in a compact megacity by landscape metrics, Journal of Environmental Engineering and Landscape Management 25: 64-74. https://doi.org/10.3846/16486897.2016.1210157 
Liu, Y.; Jiao, L.; Liu, Y.; He, J. 2013. A self-adapting fuzzy inference system for the evaluation of agricultural land, Environmental Modelling and Software Journal 40: 226-234. https://doi.org/10.1016/j.envsoft.2012.09.013

Maheshwari, B. 2016. Understanding the performance of irrigation systems around homes, Journal of Environmental Engineering and Landscape Management 24: 278-292. https://doi.org/10.3846/16486897.2016.1176575

Memmah, M. M.; Lescourret, F.; Yao, X.; Lavigne, C. 2015. Metaheuristics for agricultural land use optimization. A review. 24 p.

Mohammadi, M.; Nastaran, M.; Sahebgharani, A. 2015. Sustainable spatial land use optimization through Non-Dominated Sorting Genetic Algorithm-II (NSGA-II): (Case Study: Baboldasht District of Isfahan), Indian Journal of Science and Technology 8(3): 118-129.

https://doi.org/10.17485/ijst/2015/v8iS3/60700

Shirazi, S. M.; Adham, MD I.; Othman, F.; Zardari, N. H.; Ismail, Z. 2016. Runoff trend and potentiality in Melaka Tengah catchment of Malaysia using SCS-CN and statistical technique, Journal of Environmental Engineering and Landscape Management 24: 245-257.

https://doi.org/10.3846/16486897.2016.1184153

Pajoohesh, M.; Gorji, M.; Taheri, m.; Sarmadiyan, F.; Mohamadi, j.; Samadi, H. 2011. Effect of land use on sediment yield using GIS in Zayandehrood upstream basin, Iran Water Research Journal 5(8): 143-152 (in Persian).

Pal, B. B.; Moitra, B. N.; Maulik, U. 2003. A goal programming procedure for fuzzy multi-objective linear fractional programming problem, Fuzzy Sets and Systems 139: 395-405. https://doi.org/10.1016/S0165-0114(02)00374-3

Porta, J.; Parapar, J.; Doallo, R.; Rivera, F. F.; Sante, I.; Crecente, R. 2013. High performance genetic algorithm for land use planning, Computers, Environment and Urban Systems 37: 45-58. https://doi.org/10.1016/j.compenvurbsys.2012.05.003

Renfro, G. W. 1975. Use of erosion equations and sediment delivery ratios for predicting sediment yield. In Present and
Prospective technology for predicting sediment yields and sources, Agricultural Resources Services, ARS-S-40, US Dept. Agric., Washington, D.C. 33-45.

Rockstrom, J.; Karlberg, L. 2010. Managing Water in Rain-fed Agriculture- The need for a paradigm shift, Agricultural Water Management97(4): 543-550.

https://doi.org/10.1016/j.agwat.2009.09.009

Sahnoun, H.; Serbaji, M. M.; Karray B.; Medhioub, K. 2012. GIS and multi-criteria analysis to select potential sites of agroindustrial complex, Environmental Earth Sciences 66(8): 2477-2489. https://doi.org/10.1007/s12665-011-1471-4

Segura, M.; Ray, B. D.; Maroto, C. 2014. Decision support systems for forest management: a comparative analysis and assessment, Computers and Electronics in Agriculture Journal 101: 55-67. https://doi.org/10.1016/j.compag.2013.12.005

Shaygan, M.; Alimohammadi, A.; Mansourian, A.; Shams Govara, Z.; Kalami, S. M. 2014. Spatial multi-objective optimization approach for land use allocation using NSGA-II, Journal of Selected Topics in Applied Earth Observations and Remote Sensing 7(3): 906-916. https://doi.org/10.1109/ JSTARS.2013.2280697

Stewart, T. J.; Janssen, R. 2014. A multi-objective GIS-based land use planning algorithm, Computers, Environment and Urban Systems 46: 25-34. https://doi.org/10.1016/j.compenvurbsys.2014.04.002

Tiwari, R. N.; Dhamer, S.; Rao, J. R. 1986. Priority structure in fuzzy goal programming, Fuzzy Sets and Systems 19: 251-259. https://doi.org/10.1016/0165-0114(86)90054-0

Xiaoya, M.; Xiang, Z. 2015. Land use allocation based on a multiobjective artificial immune optimization model: an application in Anlu County, China, Sustainability 7:15 632 -15651. https://doi.org/10.3390/su71115632

Zhu, C.; Ji, P.; Li, S. 2017.Effects of urban green belts on the air temperature, humidity and air quality, Journal of Environmental Engineering and Landscape Management 25: 39-55. https://doi.org/10.3846/16486897.2016.1194276

\section{Appendix: Maps}

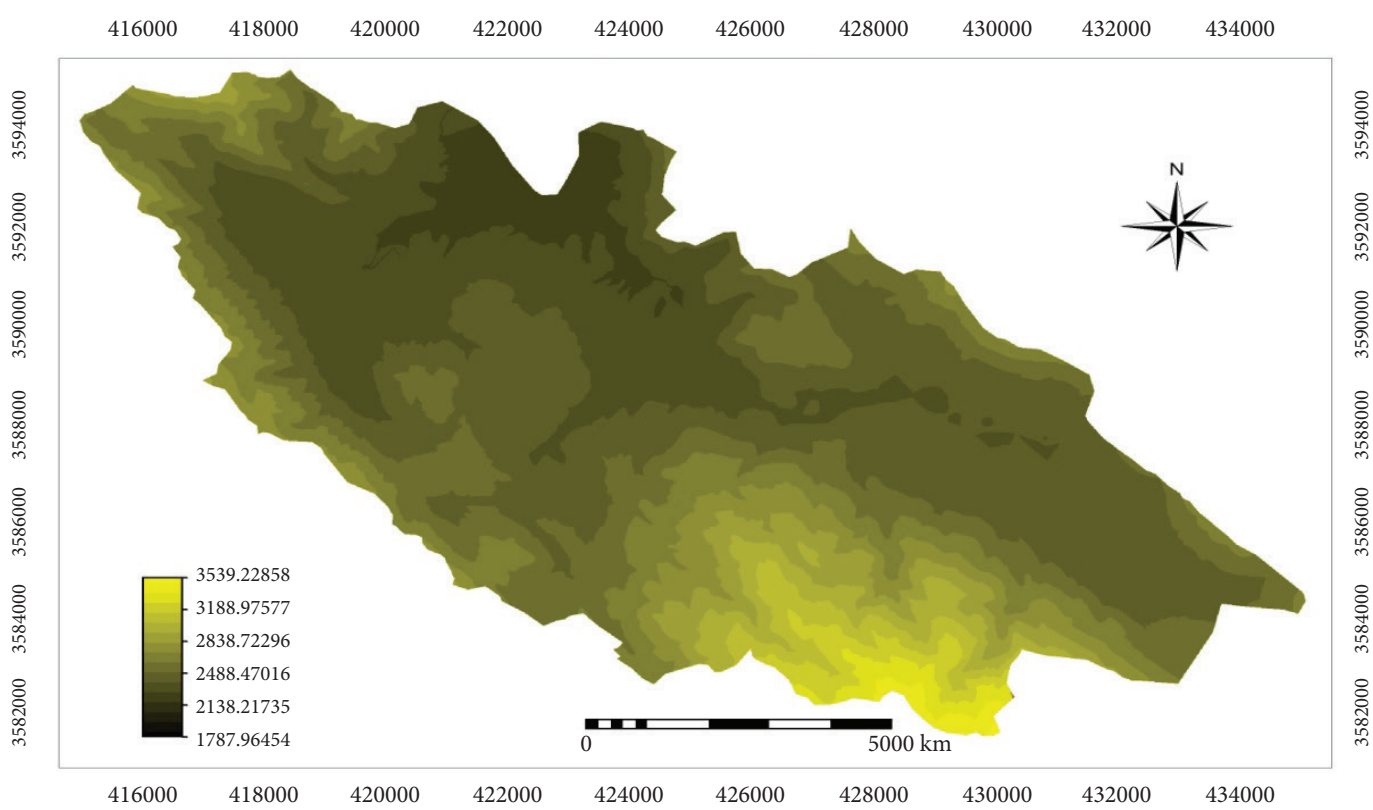

Figure 1A. Digital elevation model of the studied watershed 


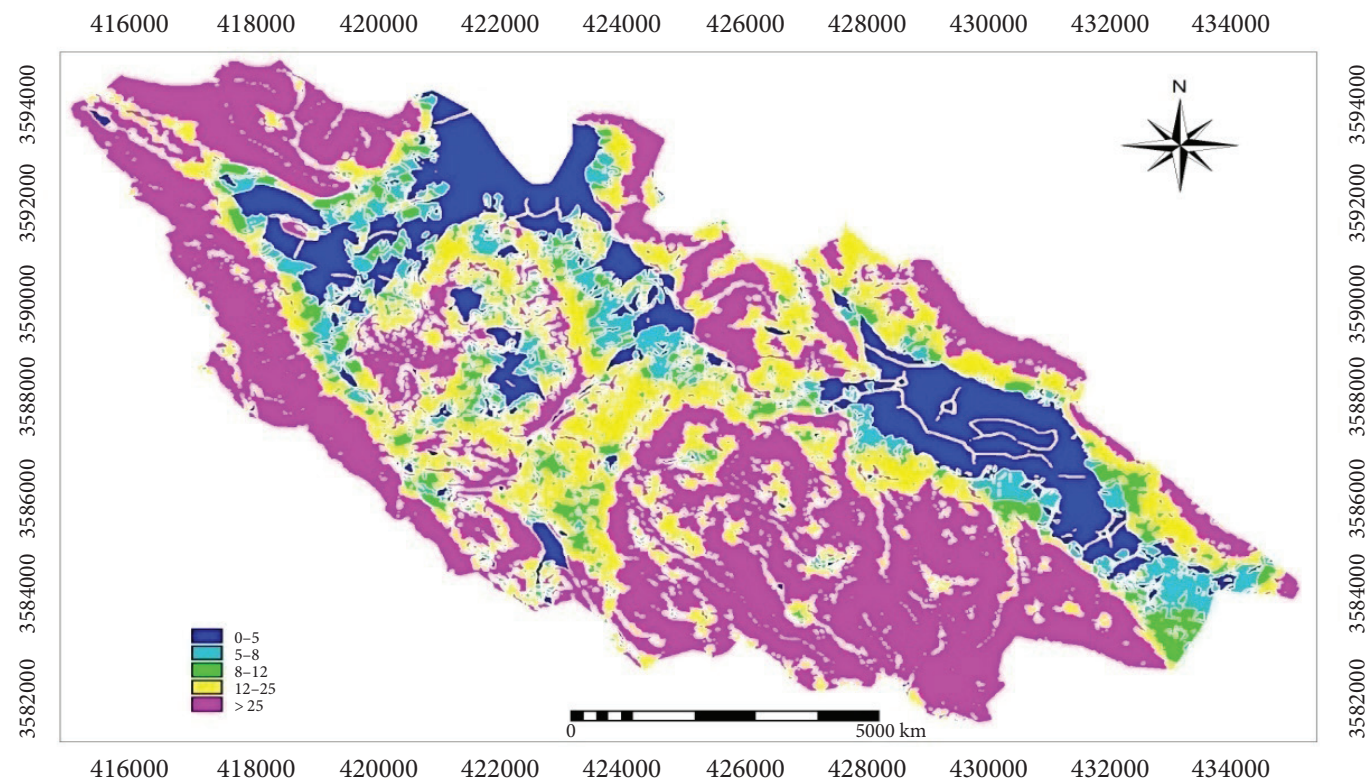

Figure 2A. Average watershed slope map of the studied watershed (in \%)

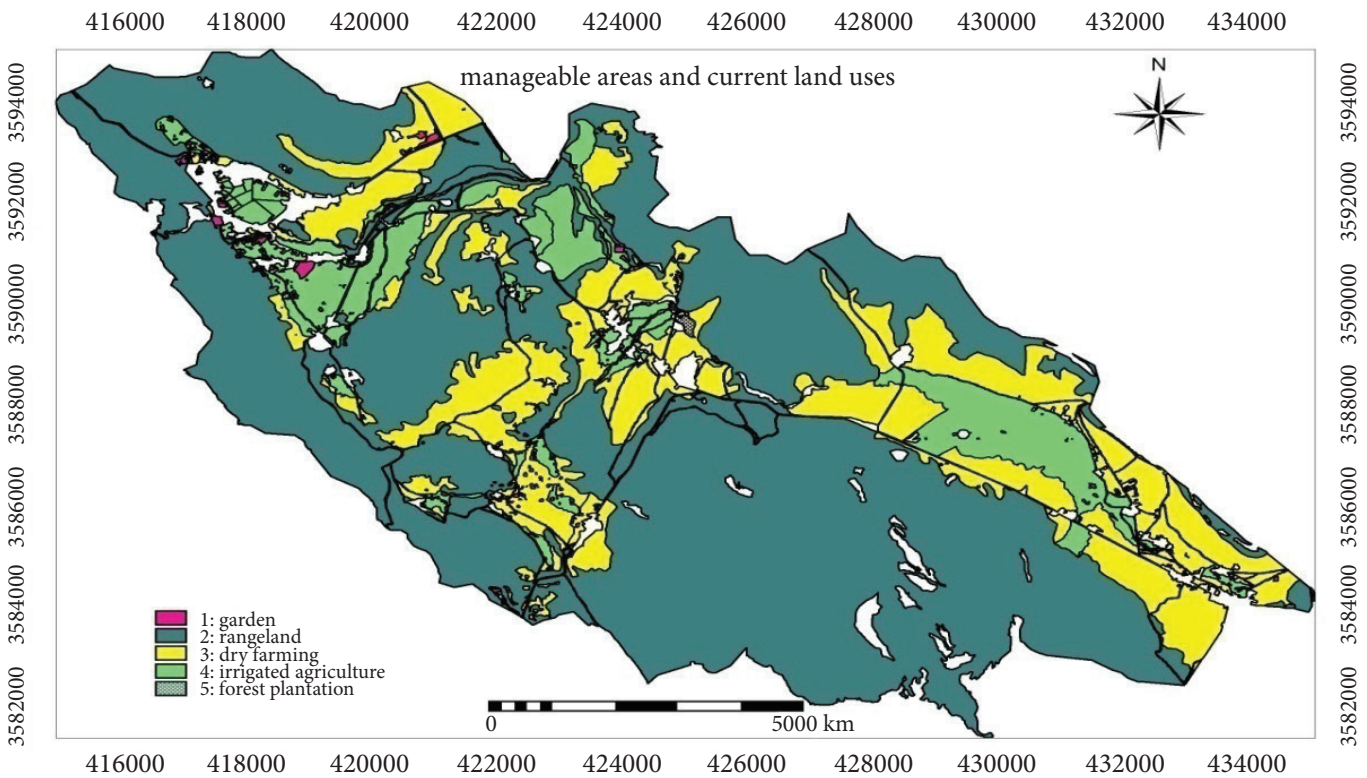

Figure 3A. Manageable areas and current land use map of the studied watershed 


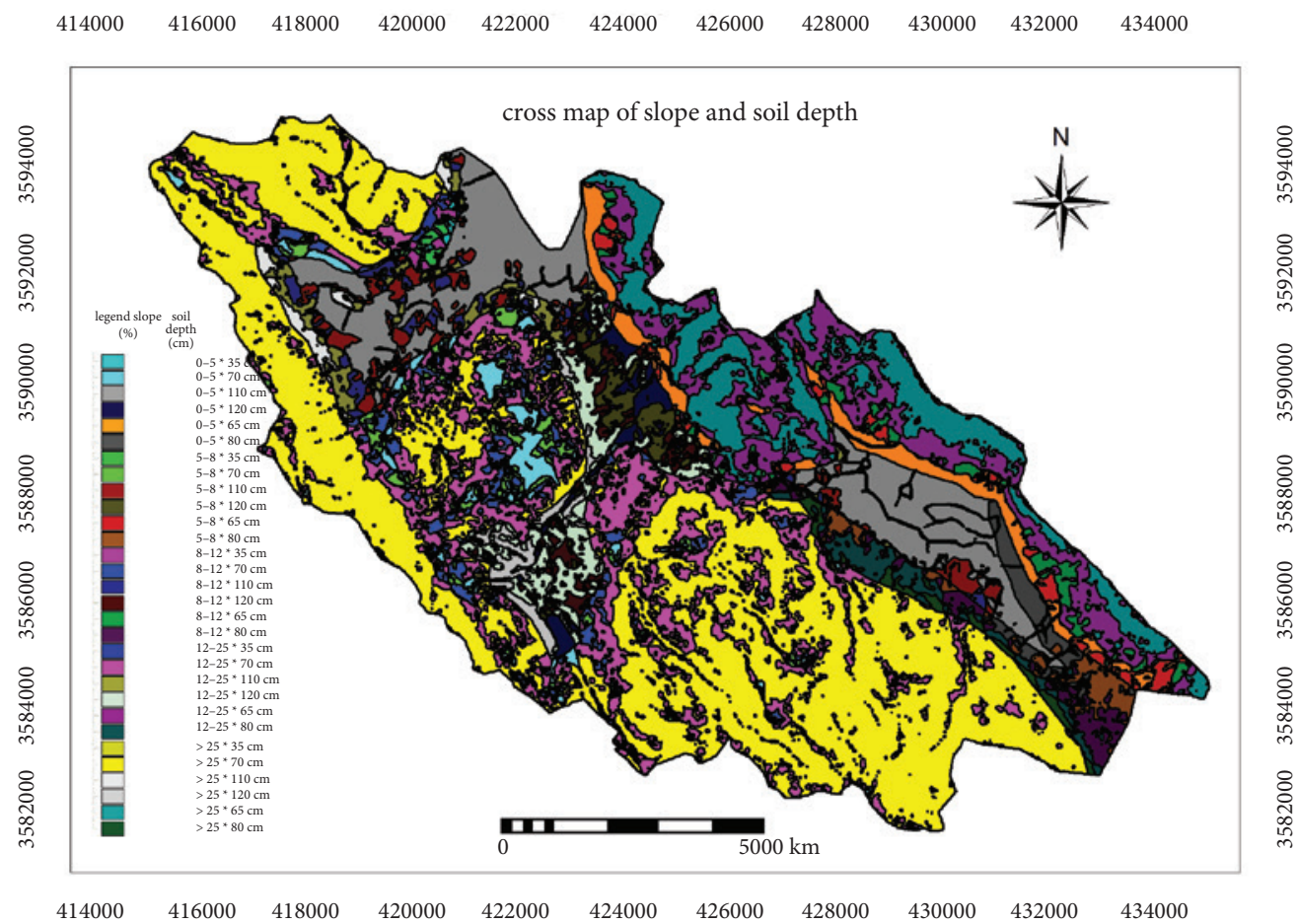

Figure 4A. A two - factor cross map of slope and soil depth criterion factors in the studied watershed

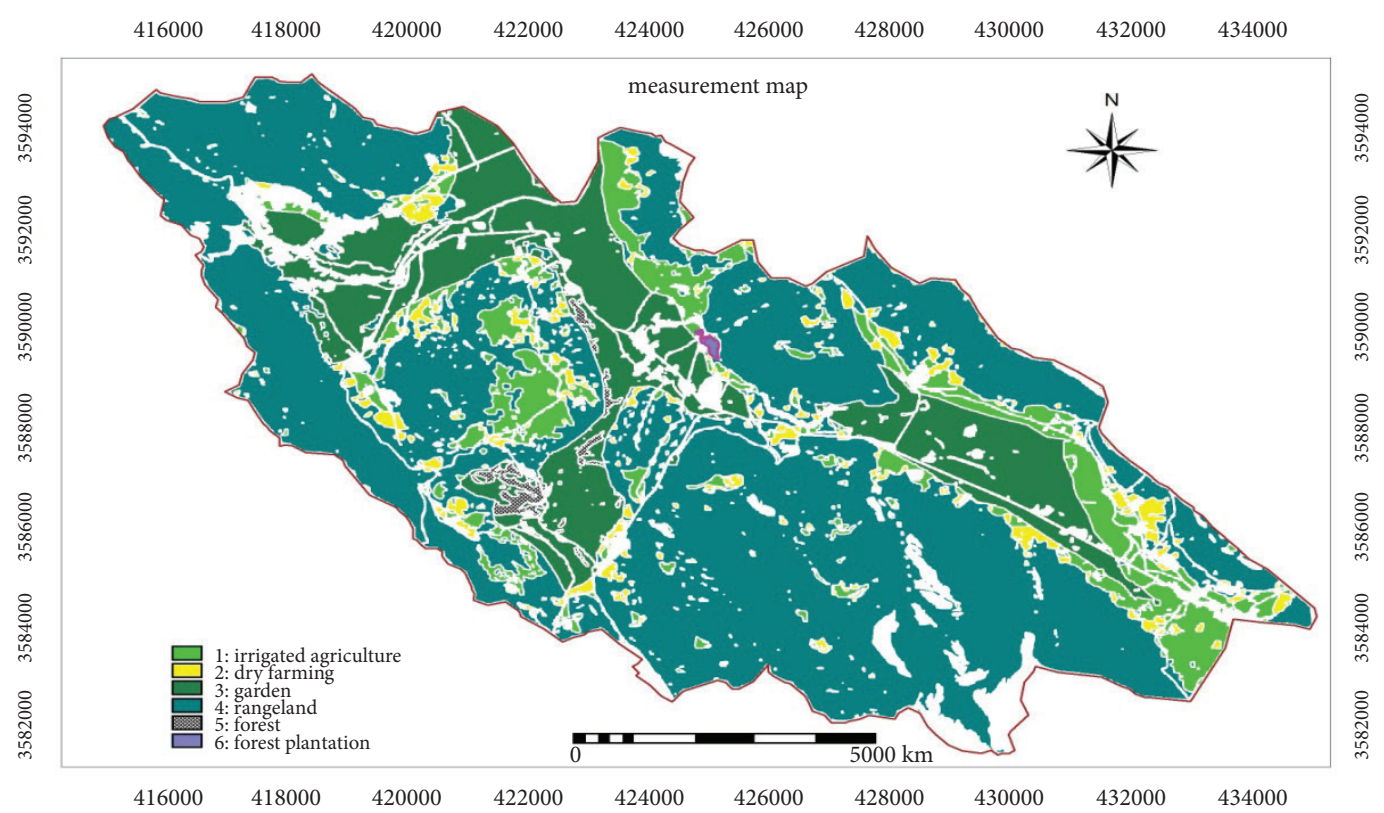

Figure 5A. Measurement land use map of the studied watershed 